\title{
Vacuum-assisted thermal bonding of plastic capillary electrophoresis microchip imprinted with stainless steel template
}

\author{
Zhifeng Chen ${ }^{\mathrm{a}}$, Yunhua Gao ${ }^{\mathrm{a}, *}$, Jinming Lin ${ }^{\mathrm{b}}$, Rongguo Su ${ }^{\mathrm{b}}, \mathrm{Yu} \mathrm{Xie}^{\mathrm{a}}$ \\ ${ }^{a}$ Technical Institute of Physics and Chemistry, Chinese Academy of Sciences, No. 3 Datun Road, Beijing 100101, China \\ ${ }^{\mathrm{b}}$ Research Center for Eco-Environmental Sciences, Chinese Academy of Sciences, Beijing 100085, China
}

Received 10 December 2003; received in revised form 15 March 2004; accepted 15 March 2004

\begin{abstract}
An improved fabrication of poly(methyl methacrylate) (PMMA)-based capillary electrophoresis microchips has been demonstrated. The microchannel structures on PMMA substrates were generated by one-step hot embossing procedure using a stainless steel template. Hundreds of patterned PMMA substrates have been successfully obtained using the single metal template. Sequent microchannel enclosure with high yield up to $90 \%$ was accomplished by a vacuum-assisted thermal bonding method. The results of profilometric scanning of separated substrates showed the dimensions of the channels were well preserved during the bonding process. Finally, analytical functionalities of these PMMA microchips were demonstrated by performing fast electrophoretic separations and high sensitive end-column amperometric detections of dopamine and catechol. The entire fabrication methodology may also be useful for preparation of other thermoplastic microfluidic systems. (c) 2004 Elsevier B.V. All rights reserved.
\end{abstract}

Keywords: Chip technology; Instrumentation; Poly(methyl methacrylate)

\section{Introduction}

In recent several years, the striking development of polymer-based capillary electrophoresis (CE) microchips has been receiving increasing attention in microfluidic system field [1-3]. In comparison to silicon or glass substrates $[4,5]$, which firstly served as the materials for original CE microchips, polymers own many advantages such as low cost, readily mechanical processing and low-temperature annealing. Especially, polymers cover a wide range of chemical, physical, and surface properties that allow great flexibility in matching materials to some specific applications. It may be predicted that the rapid growth of polymeric microfluidic devices will truly make disposable analytical microdevices possible.

Polymer microdevices can be produced by replication techniques such as imprinting [6], injection molding [7], and soft lithography [8], and by direct prototyping techniques involving laser ablation [9,10], X-ray lithography [11], low

\footnotetext{
* Corresponding author. Fax: +86-10-64879375.

E-mail address: yhgao@mail.ipc.ac.cn (Y. Gao).
}

energy ion beam etching (IBE) [12], plasma etching [13] and sacrificial etching [14]. In these fabrication methods, the imprinting approach is extremely popular due to some attractive advantages of simple procedure, low cost and suitableness of mass production. Traditional imprinting methods ordinarily involve commercial available hot-embossing systems and rigid templates with elevated pattern features as stamping tools, typically including Si [6], quartz [15] and nickel [16] templates. These templates can successfully been applied to imprint microstructures in polymer substrates. However, the $\mathrm{Si}$ or quartz templates readily tend to breakage due to different thermal expansion properties of the templates and polymer substrates in imprinting procedures. A Si template ordinarily can only be used to imprint from $\sim 10$ devices [6] to above 100 devices [17] before it has to be discarded. Nickel templates can obviate these problems. Nevertheless, high microfabrication cost and long micromachining period (ordinary above a week) for the Nickel templates limit their applications in general laboratories. Therefore, development of a cheap metal template for polymer microimprinting is undoubtedly useful.

Poly(methyl methacrylate) (PMMA) is well known from the generation of optical microdevices. It has been reported 
as the least hydrophobic of the more common plastic materials [18], and can directly generate stable electroosmotic flow (EOF) in the microchannels under the electrical field. In addition, very low material cost makes PMMA microfluidic devices very promising for generating truly integrated disposable devices for 'in-the-field' or 'point-of-care' applications.

However, compared to glass and poly(dimethylsiloxane) (PDMS) microchips, PMMA-based CE microdevices have seemed to develop limitedly. One of the main reasons is the absence of a simple but reliable sealing technique for generation of enclosed PMMA microchannel networks. Several approaches for bonding PMMA substrates have been demonstrated, including thermal bonding in a convection oven $[6,19]$, in water [20] or with heated weights $[21,22]$, thermal lamination [7], adhesive tape [23], glue layer [24], solvent bonding [25], and PDMS films [26-28]. Of these methods, thermal bonding techniques are desirable as they allow formation of microchannels with uniform surfaces composed entirely of the same polymeric materials. All these thermal bonding strategies involve applying positive pressures on the imprinted-microchannel substrates. However, slight variance of the positive pressures makes conventional thermal bonding techniques still problematic associated with microchannel deformation, reproducibility and yield. Other sealing approaches unavoidably introduce multiple materials to form microchannels with non-homogeneous internal surfaces, which leads to undesired effect on the electro-hydrodynamics of the microsystems, such as Taylor dispersion and reduced separation efficiency [29,30].

In this paper, we significantly improved the traditional imprinting and thermal bonding techniques for the fabrication of PMMA CE microchips. A stainless steel template with an intersectional relief pattern was developed to imprint microchannel networks in PMMA substrates. Subsequently, a novel vacuum-assistant thermal bonding method was applied to seal the patterned substrates. Finally analytical functionalities of the prepared CE microchips were further demonstrated by performing fast electrophoretic separations and high sensitive end-column amperometric detections of dopamine and catechol.

\section{Experimental}

\subsection{Microdevice preparation}

PMMA microdevices were made using hot embossing with a stainless steel template and vacuum bonding procedure. The metal template was generated by a modified photochemistry etching technique, as we previously had described [31]. The sections below briefly depicted the fabrication of the template and the final microchips.

A commercially available stainless steel piece with one specular surface was cleaned and dried, followed by directly spin-coating a layer of positive photoresist (BP213-45CP, (a)

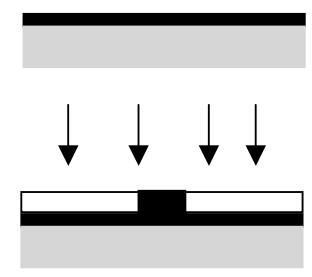

(c)

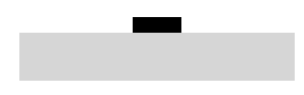

(d)

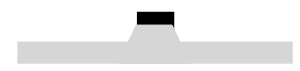

(e)

Fig. 1. Stainless steel template microfabrication. (a) A layer of photoresist (black) is spin-coated on the stainless steel plate (gray). (b) The plate is exposed to UV light through a photomask. (c) Development of the photoresist provides the surface pattern on the plate. (d) The stainless steel plate is etched in unmasked areas. (e) The residual photoresist is removed, and the template is acquired.

Chemical Reagent Institute, Beijing, China) on the specular surface (Fig. 1a). To vaporize residual solvent in the photoresist, the steel piece was baked on a hot plate at $90^{\circ} \mathrm{C}$ for $30 \mathrm{~min}$. The photoresist was then exposed to UV radiation through a patterning photomask brought into tight contact with the photoresist layer (Fig. 1b). The mask was generated using a standard Illustrator software package (Acobe Systems) to design the mask layout and then transferring it onto a photosensitive film by means of an ECRM Imaging System (make 46, ECRM, MA, USA). Following exposure, the steel piece was immersed in $0.5 \%(\mathrm{w} / \mathrm{w})$ sodium hydroxide to remove the exposed photoresist, as illustrated in Fig. 1c. To harden the remaining photoresist, the substrate was placed in an oven at $130^{\circ} \mathrm{C}$ for $60 \mathrm{~min}$. A subsequent chemical etching was performed in the mixture solution of $20 \%(\mathrm{w} / \mathrm{w})$ ferric chloride and $10 \%(\mathrm{v} / \mathrm{v})$ hydrochloride acid to form relief patterns protected by the photoresist in the steel plate (Fig. 1d). Finally, after removal of the residual photoresist with $5 \%(\mathrm{w} / \mathrm{w})$ sodium hydroxide, the stainless steel template was achieved (Fig. 1e).

The relief pattern features in the stainless steel template were imprinted into $5 \mathrm{~mm}$-thick PMMA substrates (Shenyang Lucite. Shenyang, China) in a convection oven at $140{ }^{\circ} \mathrm{C}$. First, four access holes (diameter: $2 \mathrm{~mm}$ ) were drilled to form buffer reservoirs in four appropriate positions of a $3 \mathrm{~cm} \times 6 \mathrm{~cm}$ squared PMMA piece. Next, the steel template and the drilled PMMA piece were aligned and sandwiched between two $5 \mathrm{~mm}$-thick glass plates. The assembly then was mounted into a home-made clamp apparatus. The apparatus mainly consists of a $15 \mathrm{~mm}$-thick stainless steel pressure block, a spindle, a T-bar and a force sensor. By turning tightly the T-bar, a pressure of about 12.2 MPa was applied. The entire package was placed in 
the oven for $30 \mathrm{~min}$. It then was carefully removed and gradually cooled to room temperature. Finally, the clamp was loosed and the imprinted microchannel network in the PMMA substrate was obtained.

A vacuum-assisted thermal bonding procedure was employed to seal the imprinted PMMA microchannels. The bonding process was described as follows: an imprinted PMMA piece was naturally superposed onto a $5 \mathrm{~mm}$-thick blank PMMA sheet on a $5 \mathrm{~mm}$-thick glass plate. Due to existing access holes drilled in the imprinted piece, there was no need of precise alignment between the imprinted and blank PMMA sheets. The assembly then was flatly placed in a vacuum-heating oven for $60 \mathrm{~min}$ at $112^{\circ} \mathrm{C}$ under the vacuum pressure of $10 \mathrm{mbar}$, which led to a tight bonding at the interface between the two PMMA sheets. In some cases, the surface flatness of the two superposed PMMA pieces was not high enough so that there were some opaque regions at the interface indicating incomplete bonding. As the softened PMMA sheets at $112^{\circ} \mathrm{C}$ were of viscoelasticity, the unsuccessful bonding could be simply salvaged by means of a further auxiliary thermal bonding method similar to the bonding of PDMS microdevices [8], i.e. immediately after the removal of the PMMA microdevices from the vacuum oven, the unsealed regions were lightly pressed until they just became transparent, which indicated the occurrence of the firm bonding at the interface.

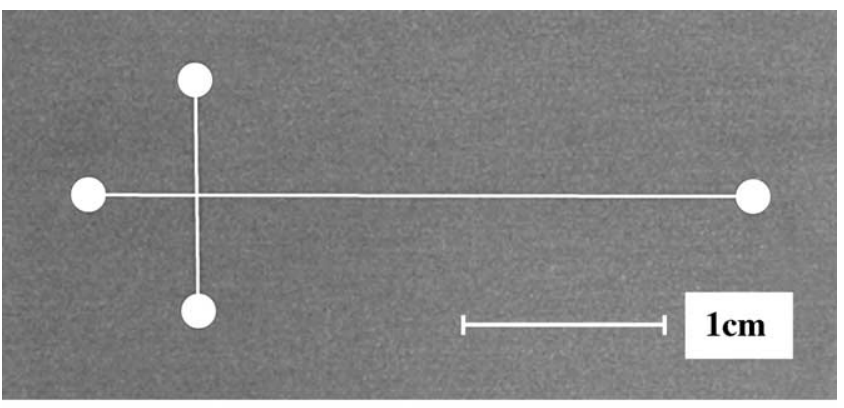

(a)

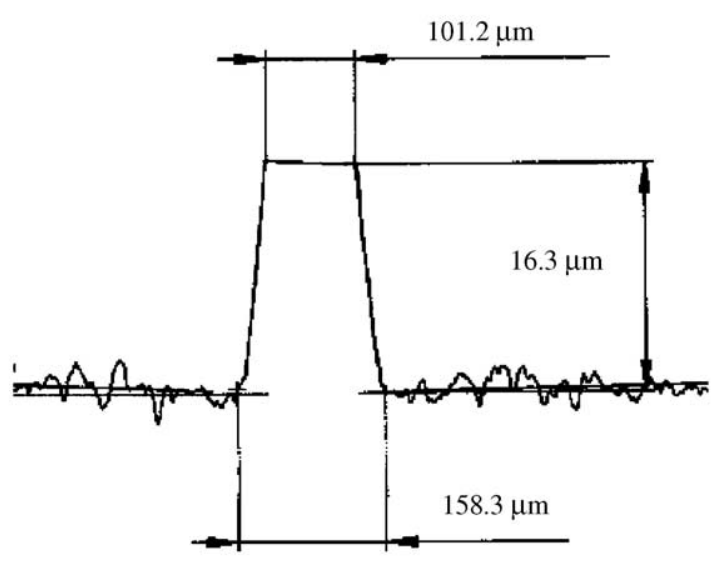

(b)

Fig. 2. (a) Photograph of the stainless steel template. (b) Cross sectional profile of the raised channel on the stainless steel template.

\subsection{Microdevice characterization}

A pulling force testing system (WDW-100A, Shijin Group, Jinan, China) was used to determine the strength of the bond between the two PMMA sheets constituting the microdevice as follows. Two home-made clamps were fixed to the top and bottom faces of the device, respectively. The assembly then was mounted into the pulling force testing system. During the trial, two pulling forces perpendicularly acted on the top and bottom faces of the device simultaneously via two force frames. The forces were increased gradually until the bonded microdevice was pulled apart. The bonding strength, $P(\mathrm{~Pa})$, can be calculated by the equation $P=F / S$, where $F$ is the biggest pulling force (N) applied onto the microdevice which still remains intact bonding, and $S$ the bonding area $\left(\mathrm{m}^{2}\right)$.

A Mahr stylus profilometer (PGK 120, Mahr, Germany) was used to measure the cross-sectional dimensions of the raised features in the stainless steel template (Fig. 2b) and of the imprinted channels both before (Fig. 3b) and after vacuum-assisted bonding. Surface profiles were obtained with $2 \mu \mathrm{m}$ lateral resolution. Microscopic images of the injection regions of both the imprinted PMMA

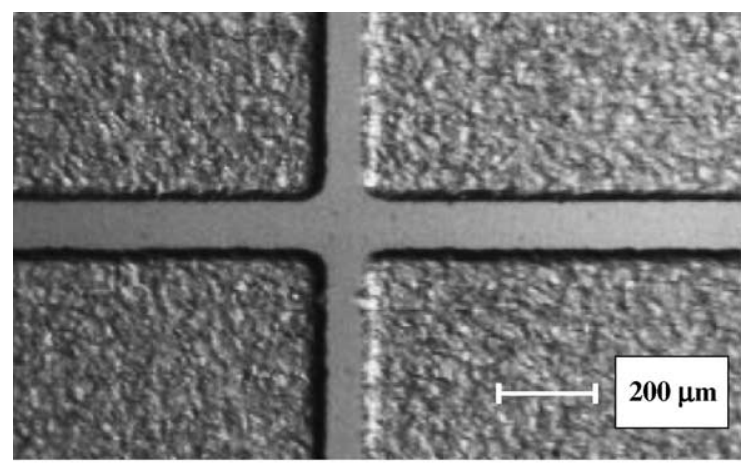

(a)

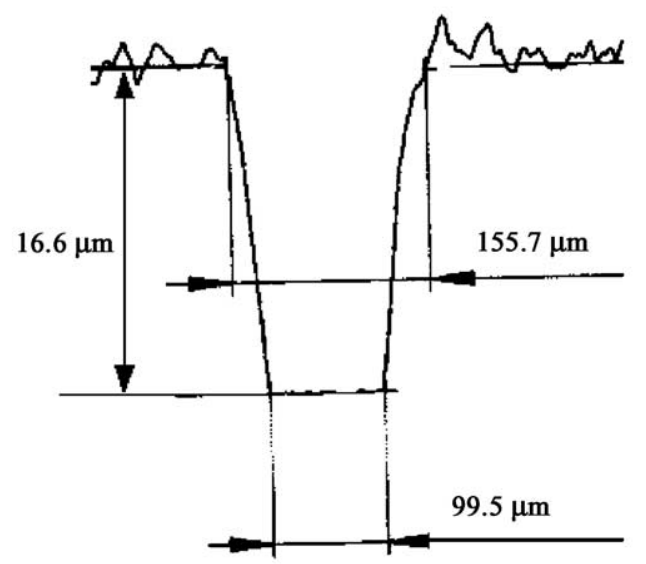

(b)

Fig. 3. (a) Microscopic image of the injection region in an open imprinted PMMA substrate. (b) Cross sectional profile of the imprinted channel on the PMMA substrate. 


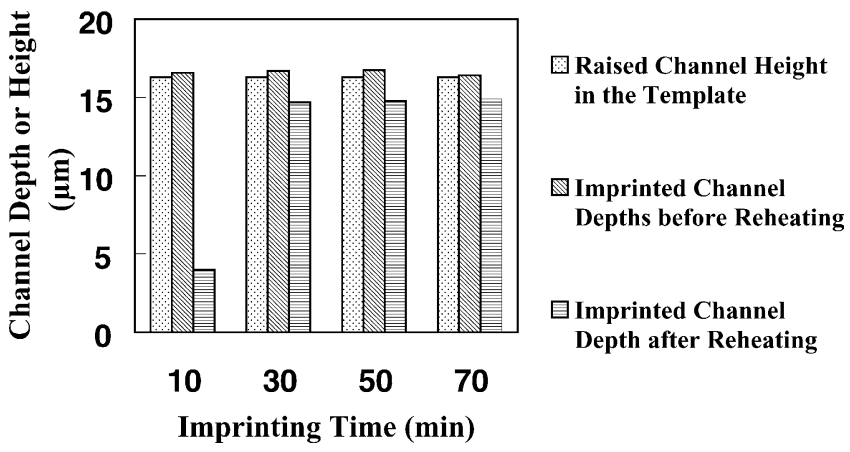

Fig. 4. Block schemes of the influence of the imprinting time on the imprinted channel depths. The reheating temperature was chosen as the thermal bonding temperature of $112^{\circ} \mathrm{C}$.

substrates and the bonded PMMA microdevices were obtained by means of an inspection microscope equipped with digital imaging system (K-400, Motic-Optic Group, Xiamen, China) (Figs. 3a, 5b and 5c). We also used Sony 717 digital camera with $5 \times 10^{6}$ pixels to give whole appearances of the templates and the microdevices (Figs. 2a and $5 \mathrm{a})$.

\subsection{Separation and detection of dopamine and catechol}

Dopamine and catechol were purchased from Sigma (St. Louis, MO, USA), and diluted in $10 \mathrm{mM}$ MES [2-( $N$-morpholino)ethanesulfonic acid, $\mathrm{pH}$ 5.7, Sigma], which also served as the run buffer. All solutions were passed through a $0.2 \mu \mathrm{m}$ filter prior to use.

A special PMMA microchip configuration is schematically displayed in Fig. 6 for the end-column amperometric detection. The chip has a $35 \mathrm{~mm}$-long separation channel (the distance from the channel intersection to the separation channel outlet) and $10 \mathrm{~mm}$-long injection channel. A reservoir with the diameter of $3 \mathrm{~mm}$ and the depth of $3 \mathrm{~mm}$ was drilled as detection cell at the end of the separation channel in the substrate plate with $5 \mathrm{~mm}$ thickness, exposing a short portion of separation channel as the guiding channel with $0.5 \mathrm{~mm}$ length for the alignment between a working electrode and the separation channel outlet. Other three holes with the diameters of $2 \mathrm{~mm}$ drilled through the coverplate were used as sample, buffer and sample waste reservoirs, respectively. Platinum wires inserted into these reservoirs provided electrical contact. Two platinum wires (diameter: $0.5 \mathrm{~mm}$ ) and an $\mathrm{Ag}$ wire (diameter: $0.3 \mathrm{~mm}$ ) coated a layer

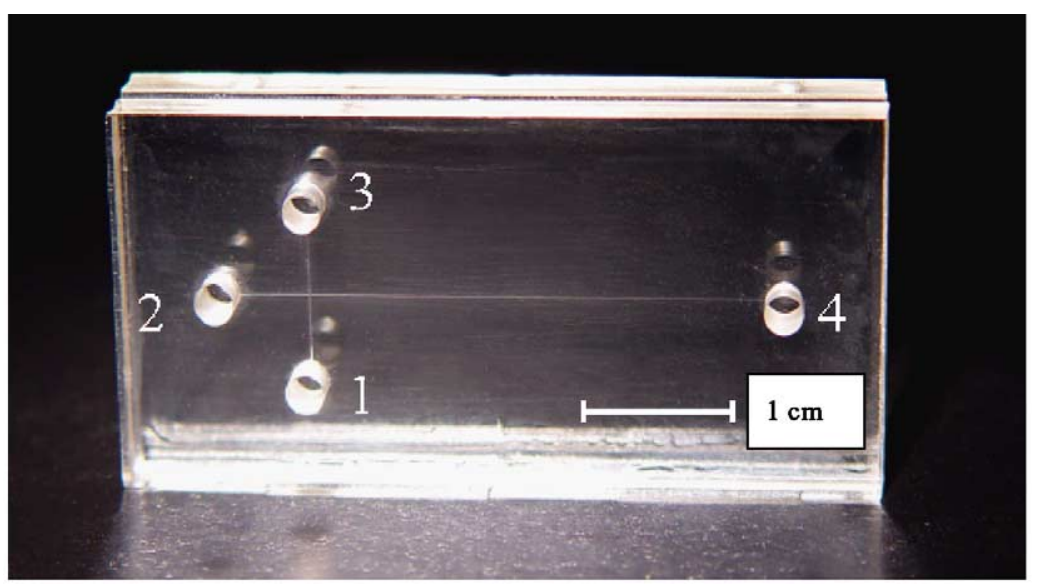

(a)

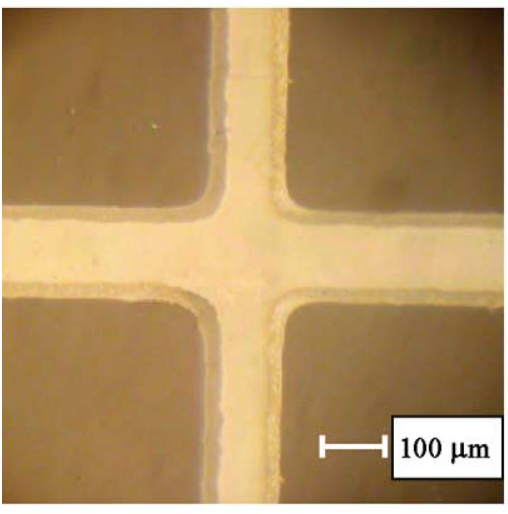

(b)

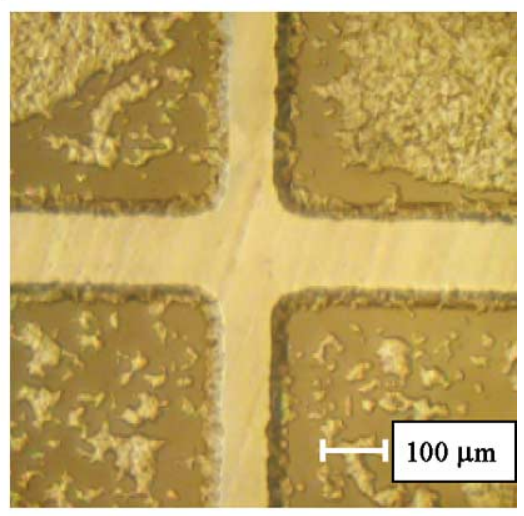

(c)

Fig. 5. (a) Photograph of an entire PMMA microdevice. (b) Microscopic image of the injection region of the PMMA microdevice bonded in the vacuum pressure of 10 mbar. (c) Microscopic image of the injection region of the PMMA microdevice bonded in the normal pressure. 


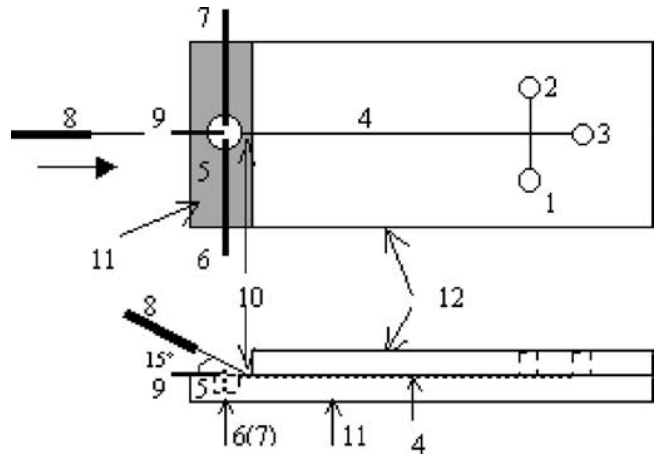

Fig. 6. Layout of the electrophoresis chip integrated with electrochemical cell. 1, Sample reservoir; 2, sample waste reservoir; 3, buffer reservoir; 4, separation channel; 5, detection cell (waste reservoir); 6, Pt wire as auxiliary electrode; $7, \mathrm{Ag} / \mathrm{AgCl}$ wire as quasi-reference electrode; 8 , $6 \mu \mathrm{m}$ carbon fiber microdisk working electrode with tip outer diameter of $20 \mu \mathrm{m}$; 9 , ground electrode; 10 , guide channel with the base width of $99 \mu \mathrm{m}$ and depth of $14 \mu \mathrm{m} ; 11$, chip substrate; 12 , chip cover plate.

of $\mathrm{AgCl}$ were inserted into the detection cell as the ground electrode, the auxiliary electrode and the quasi-reference electrode, respectively. A carbon fiber microdisk electrode, serving as the working electrode, was made via sealing a cleaned carbon fiber $(\sim 6 \mu \mathrm{m})$ into a glass tube with a prepulled conical tip (tip diameter: $0.02 \mathrm{~mm}$ ). As the guiding channel was of $\sim 14 \mu \mathrm{m}$ depth and $\sim 99 \mu \mathrm{m}$ bottom width, the working electrode was conveniently placed in the guiding channel and opposite to the channel outlet at $\sim 30 \mu \mathrm{m}$ distance at about $15^{\circ} \mathrm{C}$ angle to the substrate under the aid of a mircopositioner and an optical microscope.

The detection cell was firstly filled with the buffer solution. Due to surface tension of the buffer solution, the working electrode tip and separation channel outlet could be immersed into the solution. The channel network was then filled with the buffer solution by applying vacuum to each of the other reservoirs. A four-way high-voltage system (CDY-2001, Instrumentation Institute, Shandong, China) controlled by a personal computer was used to flexibly supply voltages to the reservoirs. Prior to sampling, the channel was electrodynamically rinsed with buffer solution for $30 \mathrm{~min}$ at the $300 \mathrm{~V} / \mathrm{cm}$ between the buffer reservoir and the grounded detection cell. The sample was loaded into the whole injection channel when an electrical field $300 \mathrm{~V} / \mathrm{cm}$ was applied between the sample reservoir and the grounded sample waster reservoir for $60 \mathrm{~s}$ with the buffer and detection reservoir floating. The sample then was injected for $1 \mathrm{~s}$ at the $300 \mathrm{~V} / \mathrm{cm}$ between the sample reservoir and the grounded detection cell with other reservoirs floating. This drove the sample "plug" into the separation channel through the intersection. By switching the high voltage contacts, separations were carried out by applying field $300 \mathrm{~V} / \mathrm{cm}$ to the buffer reservoir with the detection cell grounded and other reservoirs floating. Amperometric detection was performed using an electrochemical detection system (CDJ-2001, Instrumentation Institute, Academy of Chemical Engineering, Shandong, China) connected to a personal computer. The electropherograms were recorded with a time resolution of $0.2 \mathrm{~s}$ while applying the detection potential $0.7 \mathrm{~V}$ (versus $\mathrm{Ag}$ wire/ $\mathrm{AgCl}$ ). Sample injections were performed after stabilization of baseline.

\subsection{Safety considerations}

The $20 \% \mathrm{FeCl}_{3}$ and $10 \% \mathrm{HCl}$ used as etchants in this work are both corrosive. To avoid skin or eye contact with these solutions, safety goggles, a face shield, and elbow-length nitrile gloves should be used. The voltages used for electrophoretic injection and separation can cause electric shock. So, appropriate precautions, such as current-limiting setting on power supplies and isolation of electrical leads should be taken.

\section{Results and discussion}

For the contact photolithographic patterning procedure of the microfabrication of the stainless steel templates, a film-based photomask was developed using a photolithographic process on a photographic film (Agfa) by an ECRM Imaging System with 3546 dpi resolution. The photomask film can be comparable well with traditional chrome-quartz photomasks [32] in pattern quality, while its fabrication cost is much lower. Therefore, it should be a desired alternative for lithographic fabrication of polymer microstructures.

In the chemical etching process, to improve the adhesiveness of the spin-coated photoresist layer to the stainless steel pieces, pollutants attached onto the steel surfaces should be removed thoroughly prior to the microfabrication. The traditional surface treatment methods usually involve the use of organic solvents, which leads to some pollution problems. Here a simple and effective surface treatment method was introduced as follows: commercially available stainless steel plates with one specular surfaces coated titanium layers were immersed in the mixture solution $\left[0.5 \mathrm{M}\left(\mathrm{NH}_{4}\right)_{2} \mathrm{~S}_{2} \mathrm{O}_{8}, 0.3 \%\right.$ $(\mathrm{w} / \mathrm{w}) \mathrm{KF}, 30^{\circ} \mathrm{C}$ ] for about $8 \mathrm{~min}$ to oxidize the titanium coating, revealing the specular surfaces of the plates, followed by rinsing with deionized water and drying under nitrogen atmosphere. Other factors including photoresist characteristics, photolithographic parameters and etching environments would affect the etching resistibility of the photoresist layers too, as previous paper described [31]. Fig. 2a is the photograph of a stainless steel template fabricated using this method. Fig. $2 \mathrm{~b}$ presents the cross sectional profile of the long raised channel on the template from a stylus profilometer, which indicates that the profile is trapezoidal, and the top surface of the relief channel is very smooth, while the base surface is more rougher. This was mainly caused by the non-uniform chemical etching of the stainless steel plate containing multi-crystal compositions. As the stylus profilometer has some limitations in the side scanning, the lateral profile cannot be representative of the actual side surface characteristics of the channel. 
The prepared stainless steel template was employed in the imprinting procedure. In comparison with traditional Si templates, the stainless steel template offers several advantages. First, the imprinting process is simple. In the $\mathrm{Si}$ template-based imprinting technique applied by Kelly and Woolley [20], three steps was carefully done to avoid undue stress damaging the Si template, while in our imprinting process, due to the inherent hardness and tenacity of the steel material, only one step was necessary under a sufficient imprinting force with no anxiety of fracturing the template (detailed in Section 2). Next, the stainless steel temple is of long lifetime. After a stainless steel template was repeatedly imprinted hundreds times, no slight variance was found. As for a Si template, an imprinting yield of $\sim 100$ devices per template was already deemed to be very high [17]. Fig. 3a shows the microscopic image of the injection region in an open imprinted PMMA substrate generated using this method. As the Fig. 3b shown, the surface profile of the imprinted channel matches well with that of the raised channel on the stainless steel template by the width and depth variance within 3 and $0.5 \mu \mathrm{m}$, respectively, which was caused by the different heating expansion coefficients between the stainless steel template and the PMMA plates.

In the imprinting process, it should be noted that the elimination of interior press in polymer materials was extremely critical. Our experimental results indicated that when the imprinted PMMA substrates were reheated to the vacuum-assisted thermal bonding temperature $\left(112^{\circ} \mathrm{C}\right)$, the imprinted depths in PMMA substrates would decrease at the different extent depending on the different imprinting time (see Fig. 4), while the imprinted widths varied slightly. These phenomena attribute to the residual interior stress in the imprinted PMMA devices. In short imprinting time, stress relaxation in the deformed PMMA material was not finished thoroughly. When the polymer material was reheated to over its softening temperature, polymer chains in the material would move awards the direction of the residual interior stress, and decrease the depths of the imprinted channels. In our imprinting procedure, a $30 \mathrm{~min}$ imprinting was applied to ensure minimal decrease in the channel depths during the followed thermal bonding.

A vacuum-assisted thermal bonding method was developed to realize successfully the sealing of the patterned PMMA substrates (see Fig. 5a). Our experiments showed that under the normal atmospheric pressure, the clamp-less thermal bonding of the PMMA microchips needed not only

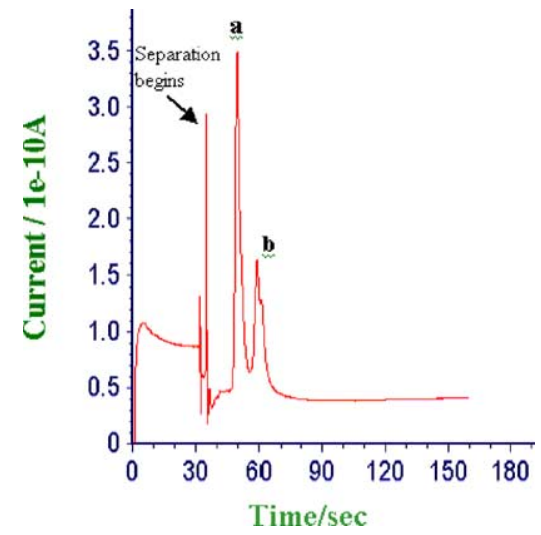

Fig. 7. Electropherogram of dopamine and catechol separated using the PMMA CE microchip with end-column amperometric detection system. The PMMA microdevice was fabricated by using a stainless steel template to imprint the PMMA substrate and bonding a PMMA cover plate to the imprinted substrate in vacuum. Peaks are: (a) $0.1 \mathrm{mM}$ dopamine; (b) $0.1 \mathrm{mM}$ catechol. Conditions: separation and injection field strength, $+700 \mathrm{~V} / \mathrm{cm}$; detection potential, $+700 \mathrm{mV} ; 6 \mu \mathrm{m}$ carbon fiber working electrode; MES buffer $(10 \mathrm{mM}, \mathrm{pH} 5.7)$ as the running buffer.

long bonding time $(2-3 \mathrm{~h})$ and high bonding temperature $\left(>116^{\circ} \mathrm{C}\right)$, but readily involved some incomplete sealing areas due to residual air in the microchips (see Fig. 5c). Herein, the introduction of the vacuum facilitated driving off the residual air and decreasing the bonding resistance. So high vacuum degree was essential for the bonding method. For the $5 \mathrm{~mm}$ thick PMMA plates applied in our experiments, the favorable bonding conditions were chosen, including the vacuum pressure of $10 \mathrm{mbar}$, the bonding temperature of $112{ }^{\circ} \mathrm{C}$ and the bonding period of $60 \mathrm{~min}$ (see Fig. 5b), while for $2 \mathrm{~mm}$ thick plates, we found that the same conditions were still suitable for the reliable bonding.

The vacuum-assisted thermal bonding method was characterized in microchannnel deformation, bonding strength and yield. As shown in Table 1, the vacuum-based bonding method was of strong bonding and high yield, while the channel deformation was comparable with the water-based bonding [20].

As further evidence of the utility of the prepared devices, we have performed $\mathrm{CE}$ analysis on a mixture of dopamine and catechol. The separation and the detection procedures were employed as described in Section 2. Fig. 7 depicts an electropherogram of the separation of $0.1 \mathrm{mM}$ dopamine and $0.1 \mathrm{mM}$ catechol. Two spikes at the beginning of the elec-

Table 1

Comparison of bonding parameters between the vacuum-assisted thermal bonding and traditional bonding methods for the sealing of PMMA microchannels

\begin{tabular}{|c|c|c|c|}
\hline Bonding methods & Bonding strength $(\mathrm{kPa})$ & Yield $(\%)$ & Decreased channel depth $(\mu \mathrm{m})$ \\
\hline Vacuum thermal bonding ${ }^{\mathrm{a}}$ & 153 (R.S.D. $=5 \%)$ & 90 & $0.3 \pm 0.07$ \\
\hline Thermal bonding in water [20] & 130 & - & $0.2 \pm 0.1$ \\
\hline Glue bonding $[24]$ & - & 60 & - \\
\hline
\end{tabular}

a The bonding strength and the decreased channel depth were averaged from six determinations of different PMMA microchips. The yield was calculated from 20 times of bonding. 
tropherogram indicate the starting of the sample injection and the sample separation, respectively. Dopamine and catechol were completely separated within $30 \mathrm{~s}$ with the separation resolution of 2.1 under the high field strength of $700 \mathrm{~V} / \mathrm{cm}$, while the detection noise was only $\sim 0.4 \mathrm{PA}$. And the limit of detection for dopamine was calculated to be $0.16 \mu \mathrm{M}(\mathrm{S} / \mathrm{N}=3)$, which is lower than $0.24 \mu \mathrm{M}(\mathrm{S} / \mathrm{N}=$ 3) acquired from a glass microchip applied by Zeng et al. [33]. Our experimental results clearly demonstrate that the PMMA CE microchips made in our methodology can be used to achieve fast CE separations and high-sensitivity detections.

\section{Conclusions}

We have demonstrated that PMMA CE microchips can be fabricated by imprinting PMMA substrates with the stainless steel templates and then vacuum-assisted thermal bonding of the substrates to blank PMMA covers. Rapid high-resolution CE separations of dopamine and catechol were successfully performed on the prepared microdevices. With the stainless steel template, the imprinting process became simpler than that with the convectional Si template. A stainless steel template can be repeatedly used to imprint hundreds of thousands polymer substrates without the fear of fracture. The thermal bonding procedure in vacuum atmosphere is readily employed, and the bonding conditions can be quantitatively controlled, which ensures high yield for the enclosure of PMMA microchannels. Moreover, the auxiliary bonding approach can supply great flexibility in integrating some microelectrodes into PMMA microdevices for electrochemical detections. In addition, this entire fabrication methodology may also be suitable for the fabrication of other thermoplastic polymer microfluidic systems.

\section{Acknowledgements}

This work was supported in part by the National High Technology Research and Development Program (No. 2001AA630503) and National Natural Science Foundation of China (No. 20275042).

\section{References}

[1] H. Becker, L.E. Locascio, Talanta 56 (2002) 267.

[2] J. Rossier, F. Reymond, P.E. Michel, Electrophoresis 23 (2002) 858.

[3] H. Becker, C. Gärtner, Electrophoresis 21 (2000) 12.
[4] Z.H. Fan, D.J. Harrison, Anal. Chem. 66 (1994) 177.

[5] S.C. Jacobson, R. Hergenroder, A.W. Moore, J.M. Ramsey, Anal. Chem. 66 (1994) 4127.

[6] L. Martynova, L. Locascio, M. Gaitan, G.W. Kramer, R.G. Christensen, W.A. MacCrehan, Anal. Chem. 69 (1997) 4783.

[7] R.M. McCormick, R.J. Nelson, M.G. AlonsoAmigo, J. Benvegnu, H.H. Hooper, Anal. Chem. 69 (1997) 2626.

[8] D.C. Duffy, J.C. McDonald, O.J.A. Schueller, G.M. Whitesides, Anal. Chem. 70 (1998) 4974.

[9] J. Rossier, F. Reymond, P.E. Michel, Electrophoresis 23 (2002) 858.

[10] M.A. Robert, J.S. Rossier, P. Bercier, H. Girault, Anal. Chem. 69 (1997) 2035.

[11] K. Ueno, F. Kitagawa, H.B. Kim, T. Tokunaga, S. Matsuo, H. Misawa, N. Kitamura, Chem. Lett. 8 (2000) 858.

[12] L.P. Lee, S.A. Berger, L. Pruitt, D. Liepmann, in: D.J. Harrison, A. van den Berg (Eds.), Micro Total Analysis Systems 1998, Kluwer, Dordrecht, 1998, p. 245.

[13] J.S. Rossier, A. Schwarz, F. Bianchi, F. Reymond, R. Ferrigno, H.H. Girault, Micro Total Analysis Systems 2000, Kluwer, Dordrecht, 2000, p. 159.

[14] J.R. Webster, M.A. Burns, D.T. Burke, C.H. Mastrangelo, in: D.J. Harrison, A. Van den Berg (Eds.), Micro Total Analysis Systems 1998, Kluwer, Dordrecht, 1998, p. 249.

[15] G.B. Lee, S.H. Chen, G.R. Huang, W.C. Sung, Y.H. Lin, Sens. Actuators B 75 (2001) 142.

[16] J. Elders, H.V. Jansen, M. Elwenspoek, W. Ehrfeld, in: Proceedings of the MEMS'95, Amsterdam, 1995, p. 238.

[17] J. Xu, L. Locascio, M. Gaitan, C.S. Lee, Anal. Chem. 72 (2000) 1930.

[18] H. Bayer, H. Engelhardt, J. Microcol. Sep. 8 (1996) 479.

[19] M. Galloway, W. Stryjewski, A. Henry, S.M. Ford, S. Liopis, R.L. McCarley, S.A. Soper, Anal. Chem. 74 (2002) 2407.

[20] R.T. Kelly, A.T. Woolley, Anal. Chem. 75 (2003) 1941.

[21] S.M. Ford, J. Davies, B. Kar, S.D. Qi, S. McWhorter, S.A. Soper, C.K. Malek, J. Biomech. Eng. 121 (1999) 13.

[22] S.M. Ford, B. Kar, S. McWhorter, J. Davies, S.A. Soper, M. Klopf, G. Calderon, V. Saile, J. Microcol. Sep. 10 (1998) 413.

[23] L.G. Song, D.F. Fang, R.K. Kobos, S.J. Pace, B. Chu, Electrophoresis 20 (1999) 2847.

[24] B. Grass, A. Neyer, M. Jöhnck, D. Siepe, F. Eisenbeiß, G. Weber, R. Hergenröder, Sens. Actuators B 72 (2001) 249.

[25] J. Wang, M. Pumera, M.P. Chatrathi, A. Escarpa, R. Konrad, A. Griebel, W. Dörnger, H. Löwe, Electrophoresis 23 (2002) 596.

[26] J.D. Xu, L. Locascio, M. Gaitan, C.S. Lee, Anal. Chem. 72 (2000) 1930.

[27] S.L.R. Barker, M.J. Tarlov, H. Canavan, J.J. Hickman, L.E. Locascio, Anal. Chem. 72 (2000) 4899.

[28] D.L. Pugmire, E.A. Waddell, R. Haasch, M.J. Tarlov, L.E. Locascio, Anal. Chem. 74 (2002) 871.

[29] F. Bianchi, F. Wagner, P. Hoffmann, H.H. Girault, Anal. Chem. 73 (2001) 829.

[30] Y. Liu, J.C. Fanguy, J.M. Bledsoe, C.S. Henry, Anal. Chem. 72 (2000) 5939.

[31] Z. Chen, Y. Gao, R. Su, C. Li, J. Lin, Electrophoresis 24 (2003) 3246.

[32] S.C. Jacobson, L.B. Koutny, R. Hergenröder, A.W. Moore, J.M. Ramsey, Anal. Chem. 66 (1994) 3472.

[33] Y. Zeng, H. Chen, D.-W. Pang, Z.-L. Wang, J.-K. Cheng, Anal. Chem. 74 (2002) 2441. 